\title{
Economía, rentas y situados en Cartagena de Indias, 1761-1800
}

\author{
José Manuel Serrano Álvarez. \\ Universidad de Sevilla
}

\begin{abstract}
Partiendo de un riguroso análisis de las cajas reales con una metodología concisa y minuciosa, este artículo pretende demostrar que el situado que entró en Cartagena de Indias entre 1761 y 1800, aunque fue de gran importancia para el desarrollo de la administración militar, sólo tuvo un impacto indirecto en la economía local. La base del análisis es la comparación entre las rentas más características de la Cartagena de finales del XVIII y los situados, así como las posibles repercusiones sobre diversos impuestos. El conjunto de datos, gráficas y análisis hace hincapié en la simbiosis entre administración militar y economía local, pero también muestra cómo la guarnición de Cartagena se soportó en las últimas décadas del siglo especialmente con una parte cada vez más sustancial de las rentas provenientes del comercio exterior, lo que sin duda hizo disminuir mucho el posible impacto del situado en la vida económica y social de la ciudad.
\end{abstract}

PALABRAS ClAVE: rentas, situado, economía, Cartagena, administración militar, guarnición, fortificación, defensa, gasto militar

Based on extensive research of the royal treasury with a concise and detailed methodology, this article shows that the situado which arrived at Cartagena de Indias between 1761 and 1800, although of great importance for the purposes of the military, only had an indirect impact upon the local economy. This analysis is based upon a comparison between the tax revenues most prominent for Cartagena toward the end of the eighteenth century and the situados, as well as the possible repercussions on various levies. The combination of data, graphs, and analysis highlights the symbiosis between the military administration and the local economy, but it also shows how the Cartagena garrison was supported during the closing decades of the century, especially with an increasingly substantial portion of the revenues generation from overseas commerce, which undoubtedly reduced much of the actual impact of the situado on the economic and social life of the city.

Keywords: income, situado, economy, cartagena, military administration, garrison, fortification, defense, military expenditure

Actualmente hay una tendencia dentro de los estudios americanistas referentes al papel de la administración militar sobre el organigrama civil y económico de las colonias españolas que viene atribuyendo una importancia casi decisiva a los situados como factor revitalizador de las economías 
locales. No son pocos los autores que ubican a los situados por encima incluso de las rentas en orden a la importancia cuantitativa y cualitativa que tenían para el sostenimiento financiero de la administración castrense. No dudamos de la importancia de los situados como mecanismos correctores de la economía de una ciudad determinada e incluso de un territorio más o menos amplio. Es más, podemos afirmar que los flujos de capital entre distintas guarniciones representaban una ayuda inestimable para mantener la cohesión interna de factores de índole económica. Sin embargo, la afirmación de que los situados constituían los elementos no sólo decisivos sino también determinantes en el crecimiento económico de una ciudad, como era el caso de Cartagena de Indias, se nos antoja cuando menos excesivo.

\section{Conceptos}

En 1982 el historiador Juan Marchena, en su momento uno de los pioneros en España de los estudios de la administración militar en Indias, propuso una idea según la cual el ciclo económico de Cartagena de Indias durante el siglo XVIII dependía de los situados. ${ }^{1}$ No hacía referencia directa ni cuantificaba qué eran las rentas, cómo funcionaba realmente la economía cartagenera y cuáles eran las bases de los mecanismos de ingresos y gastos de la administración de la ciudad. Al hilo de esto se decía que los situados constituían la clave de la economía local, ya que de su llegada o no dependía que la clase comerciante local pudiera disponer de liquidez para sufragar la defensa de la ciudad vía impuestos o entregas directas. La clave de la idea de Marchena estribaba en que la fortaleza de la economía cartagenera permitía a los comerciantes sufragar la defensa siempre y cuando los soldados dispusieran del capital que representaban los situados. O dicho de otra forma, si los soldados disponían de liquidez, vía situado, éstos podían comprar a los comerciantes que a su vez mantenían, en gran medida, la defensa de la ciudad con sus impuestos. No está claro cómo se cerraba el círculo y desgraciadamente no tenemos pruebas documentales de la efectiva relación entre la clase comercial y el capital entrante vía situados.

1 Marchena Fernández, Juan: La institución militar en Cartagena de Indias 1700-1810, Escuela de Estudios Hispanoamericanos, Sevilla, 1982, pág. 268-271. Obra, por lo demás, muy interesante en otros aspectos de la administración militar cartagenera. 
En 2002 el economista colombiano Adolfo Meisel apuntó en una dirección similar. ${ }^{2}$ Basándose en una sólida argumentación de terminología económica, Meisel llega a la conclusión de que la economía de Cartagena de Indias era esencialmente dependiente de los situados y, por tanto, el crecimiento de las rentas en la segunda mitad del siglo XVIII se debió en realidad al incremento de los depósitos de capital provenientes del exterior. Mediante la técnica de reducción de posibilidades, Meisel indica en su estudio que el incremento de la actividad económica cartagenera no pudo deberse ni al aumento de la inflación, ni al incremento de la población, ni tampoco a los ingresos per cápita o a una elevación de la presión fiscal. En vista de ello, sólo quedaba como explicación plausible el recurso al situado como motor de la economía local. En un reciente y muy interesante Simposio Internacional dedicado al estudio de los situados en todo el ámbito americano, Meisel volvió a incidir en este aspecto, uniendo a los consabidos argumentos el de que el comercio local no constituía un factor significativo de la actividad económica de Cartagena. ${ }^{3}$ En un artículo reciente y bastante similar incide en el mismo punto, pero haciendo incluso extensiva a gran parte de la Nueva Granada su teoría de la influencia de los situados. ${ }^{4}$

Pensamos que todas estas argumentaciones acerca del peso de los situados hacen hincapié en el recurso a la dependencia externa de los principales enclaves americanos, tal vez para poder explicar mejor el papel de ciertas entidades políticas en los procesos independizadores de comienzos del siglo XIX, o para poder resaltar la importancia de las interrelaciones económicas en el posterior ámbito histórico de Colombia.

La ausencia de conceptuación a la hora de exponer argumentos de índole económica viene siendo un error que debemos precisar aquí. Los argumentos expuestos arriba carecían, en nuestra opinión, de conceptos nítidos acerca de qué eran las rentas de la Real Hacienda, cómo funciona-

2 Meisel Roca, Adolfo: "Crecimiento a través de los subsidios: Cartagena de Indias y el situado, 1751-1810" en Cuadernos de Historia económica y empresarial, Cartagena de Indias, 2002, n. ${ }^{\circ}$, abril.

3 Meisel Roca, Adolfo: “Situado o contrabando? La base económica de Cartagena de Indias a fines del siglo de las Luces”, desarrollado durante el Simposio Internacional El situado en el Imperio colonial español, Cartagena de Indias, 28-29 agosto de 2003.

4 Meisel Roca, Adolfo: “Situado o contrabando?: La base económica de Cartagena de Indias y el Caribe neogranadino a fines del Siglo de las Luces”, Cartagena de Indias en el siglo XVIII, Banco de la República, Cartagena, 2005. 
ban, cuáles eran sus cauces naturales, cómo se repartían, y qué eran desde el punto de vista económico los situados.

En esencia, para establecer una adecuada y correcta relación entre los situados y las rentas de una determinada caja real, o para analizar la relación de causalidad entre situados y economía local, resulta imprescindible establecer una serie de conceptos previos. Desde nuestro punto de vista, es necesario realizar las siguientes tareas conceptuales: 1.-Qué eran las rentas de Cartagena, y cuáles utilizar como elementos de comparación con el situado, 2.-Cómo funcionaban las rentas, en el sentido de determinar si provenían de circuitos internos o externos a la ciudad, 3.-Qué rentas podían estar más o menos vinculadas con la administración militar de la ciudad, 4.-Cuál era el posible entramado jurídico que establecía relaciones directas entre las rentas y el gasto militar de la guarnición, y entre el situado y su peso teórico en el conjunto de los gastos de la administración castrense, y 5.-En qué consistía realmente el situado y cómo funcionaba. La respuesta a todos estos interrogantes llevaría necesariamente a resolver la cuestión de si los situados constituían un elemento más de los que hacían posible girar la rueda de las economías locales en torno a las guarniciones americanas, o si por el contrario, el situado resultaba ser el verdadero motor de dichas economías.

No tenemos dudas acerca de que el situado como suplemento de capital externo a una guarnición suponía un acicate, o cuando menos, un elemento capaz de incidir más o menos directamente en la dinámica económica de una ciudad. Las aportaciones de capital provenientes de los situados repercutían, como no podía ser de otra forma, sobre la evolución de las transacciones locales, lo que necesariamente tendría un reflejo en determinados impuestos y rentas a cobrar por la administración. Dado que la administración militar absorbía enormes cantidades de dinero y que la población militar de la gobernación de Cartagena era muy importante, es lógico pensar que directa o indirectamente suponían un refuerzo económico para la ciudad. ${ }^{5}$ Lo que no está en absoluto claro es que el capital exterior que provenía esencialmente para la paga de la guarnición (los situados) resultaba el elemento que sostenía la economía, porque eso es tanto como afirmar que la economía cartagenera entre 1760 y 1800 estaba virtualmente estancada, y que estaba subsidiada desde el exterior gracias a los militares. pág. 69.

5 Meisel Roca, A.: “Situado o contrabando?: La base económica de Cartagena de Indias..., 
Como veremos seguidamente, en Cartagena de Indias el situado fue un elemento del entramado económico de la ciudad, pero no más. ${ }^{6}$

Es imprescindible, por tanto, conocer qué elementos son los adecuados para ponerlos en relación con el flujo de situados hacia Cartagena de Indias durante el siglo XVIII. Habitualmente se han utilizado como objeto de referencia los sumarios de cargo y data sin la más mínima depuración, y sin una especificación clara de qué rentas se iban a usar. Por lo demás, prácticamente nunca se aclara qué factores han determinado que se escoja unos datos con preferencia sobre los demás. En este punto, aún se siguen utilizando profusamente las series publicadas en su momento con gran esmero por Tepaske y Klein acerca de las tesorerías reales americanas, sin ningún tipo de depuración contable, exponiendo, o más bien, transcribiendo literalmente los sumarios. Décadas después sabemos que el uso y abuso de estas series no sólo no reflejan la realidad contable y económica de las diferentes tesorerías, sino que además tiende a distorsionarlas. ${ }^{7}$

Sin entrar en ningún debate acerca del concepto renta, ya que las palabras renta o impuesto tienen muchas connotaciones, aquí lo que se pretende es dilucidar la manera en que un capital determinado, en concreto el situado, puede influir en los mecanismos que producen riqueza en una ciu$\mathrm{dad},{ }^{8} \mathrm{y}$, más exactamente, en comparación con determinadas rentas locales.

Un elemento de vital importancia a tener en cuenta a la hora de relacionar el situado con su incidencia sobre un enclave determinado es su propia conceptuación y naturaleza. Nadie se ha parado, hasta ahora, a determinar qué eran realmente los situados, cuál era su estructura jurídica y sobre qué elementos de una guarnición estaban destinados. En nuestro reciente estudio 9 al respecto se han podido determinar todos estos aspectos, sin los

6 En el último trabajo de Adolfo Meisel, “¿Situado o contrabando?: la base económica de Cartagena de Indias a fines del siglo de las Luces”, Cuadernos de Historia Económica y Empresarial, Cartagena, diciembre 2003, n. ${ }^{\circ} 11$, el autor vuelve a incidir en la idea de que el situado era una transferencia de capitales para todo tipo de gastos militares. Sin embargo, no hemos apreciado ninguna prueba documental que sostenga esta idea. Si bien es cierto que del situado se podían desviar cantidades para otros menesteres, esto era una práctica jurídicamente alegal, que constituía la excepción y no la regla general.

7 Serrano Álvarez, José Manuel: "Introducción a la metodología del gasto militar en Indias", Temas Americanistas, Universidad de Sevilla, Sevilla, 2002, n. ${ }^{\circ}$ 15, págs. 32-38.

8 Para Adolfo Meisel, la base económica "de una región o ciudad la constituyen aquellas actividades que determinan el comportamiento económico global. Típicamente, la base económica se identifica con el sector exportador de bienes y servicios”, en “¿Situado o contrabando?..., pág. 5.

9 Serrano Álvarez, José Manuel: Fortificaciones y tropas. El gasto militar en Tierra Firme, 1700-1788, Universidad de Sevilla, Consejo Superior de Investigaciones Científicas, Diputación de Sevilla, Sevilla, 2004. 
cuales difícilmente se podrá entender la mecánica de los situados o apoyar cualquier intento de explicación veraz de la influencia real que tienen los situados sobre las economías locales. El situado es, jurídicamente, una ayuda vía depósito de capital que la corona española instauró hacia finales del siglo XVI para mantener la defensa de las guarniciones con menos recursos económicos, pero que no será hasta el XVIII cuando alcance su máxima expansión y desarrollo, constituyéndose en un aspecto clave de la defensa de América. Económicamente, el situado es una mera transferencia de capital desde una caja matriz a otra subalterna, mientras que administrativamente, no es más que la aportación fijada obligatoriamente sobre una caja matriz que debe sufragar en todo o en parte las tropas de una guarnición, es decir, su componente humano. ${ }^{10}$

No se ha encontrado ningún documento que haga referencia al situado como elemento de financiación de las fortificaciones o de los gastos navales. Es cierto que en algunos documentos provenientes de la caja de México se hacía constar la expresión situado del tabaco, pero en realidad suponía claramente un uso tangencial y burocrático de una palabra que venía siendo usada desde hacía más de un siglo para referirse a las transferencias de capital. Es bien conocido que las fortificaciones y las flotas debían ser pagadas por las rentas, los vecinos y los comerciantes de una ciudad que eran, a la postre, los más interesados en el sostenimiento de las defensas estáticas y navales. Todo ello está claramente expuesto en la Recopilación de las Leyes de Indias de $1680 .{ }^{11}$ La palabra y el concepto de situado aparecía siempre ligado a las tropas, y así se hacía constar en cada reglamento que establecía un batallón o regimiento fijo en cualquier parte de la América hispana. No cabe duda de que si el situado hubiera sido un factor ligado teórica o jurídicamente a cualquier otro elemento distinto de las tropas, éste habría estado reflejado en multitud de documentos, reglamentos y órdenes. Por tanto, considerar el situado como una transferencia de la que se hacía uso indiscriminado para cualquier necesidad de índole militar es sencillamente erróneo. Las fortificaciones eran pagadas tanto en Cartagena de Indias como en la mayoría de las guarniciones importantes americanas por los impuestos locales, préstamos individuales y de comer-

10 Serrano Álvarez, José Manuel: "El factor humano en la defensa de Tierra Firme", Temas Americanistas, Universidad de Sevilla, Sevilla, 2003, n. ${ }^{\circ}$ 16, págs. 27-35.

11 Calderón Quijano, José Antonio: Las defensas indianas en la Recopilación de 1680, Escuela de Estudios Hispanoamericanos, Sevilla, 1984. Libro que expone muy claramente la distinta vinculación económica entre los diferentes elementos de los sistemas defensivos indianos. 
ciantes y transferencias directas desde cajas exteriores con ese único fin, y ningún documento de la época llama a estos envíos de dinero con la palabra situado. Las fortificaciones en Cartagena recibían en ocasiones transferencias directas de Santa Fe, las de La Habana de México (vía Veracruz), o las de Panamá de Lima, al tiempo que además todas y cada una de estas guarniciones tenían su propio e independiente situado que nada tenía que ver con las remisiones para las defensas fortificadas.

Obviamente estas características son de tipo general y aplicables a todo el ámbito indiano. No se nos escapa, empero, que en determinadas zonas y momentos históricos hubo ciertas desviaciones con respecto a estas particularidades, que constituyen, sin embargo, la excepción que confirma la regla. Así, en ocasiones hemos observado cómo en Cartagena u otros lugares era usado parte del situado para diferentes fines militares, casi siempre relacionados con las fortificaciones. Además, en otras áreas geográficas una parte del situado se hacía llegar en especie en vez de en metálico, e incluso se suministraba parte del situado en especie para ser vendida y aplicado el producto final a la tropa. ${ }^{12} \mathrm{El}$ situado aparece así como un elemento firmemente ligado a las tropas, no sólo desde el punto de vista práctico, sino también jurídico. Todas las disposiciones relativas al situado, que no enumeraremos aquí por ser muy extensas y repetitivas, indican con claridad que el destino último del situado es la tropa y su mantenimiento. Sus pagas, por tanto, proceden en todo o en parte de este capital suministrado desde el exterior y administrado por las autoridades locales.

Este fue el caso de Cartagena de Indias a lo largo del siglo XVIII. Este vital puerto de entrada del Nuevo Reino recibió siempre el situado en metálico, siendo, de esta forma, una mera transferencia de capital procedente de Quito y Santa Fe, ambas obligadas desde finales del siglo XVII a suministrar a Cartagena apoyo financiero para sus tropas. Además, excepto en determinadas y muy puntuales circunstancias, el situado se utilizó exclusivamente para las pagas de la guarnición militar y de sus milicias. Los gastos navales salieron en su mayor parte de las arcas de la ciudad y de remisiones especiales de Santa Fe o Quito, y las fortificaciones, al contrario de lo que algunos autores defienden, fueron sufragadas casi exclusivamente con los impuestos de la ciudad y gracias a préstamos tanto de vecinos,

12 El primer caso es aplicable a La Florida en la primera mitad del siglo XVIII, mientras que el segundo fue una práctica habitual en el caso del situado de La Habana durante la segunda mitad del siglo, cuando en determinados años se enviaba tabaco para ser vendido y aplicado el resultante final a la guarnición habanera. 
como de comerciantes del lugar. Por tanto, una parte muy significativa de los gastos militares de Cartagena no procedían del situado, sino que forzosamente debían de proceder de algunos de los otros dos canales de financiación militar de cualquier plaza indiana: las rentas locales y los préstamos. Las cifras muestran unas conclusiones muy interesantes a este respecto. Entre 1700 y 1788 el Fijo de Cartagena y las compañías de artillería, que eran sobre las que teóricamente se establecía el situado, absorbieron el $61,3 \%$ de todos los gastos militares de la ciudad, ${ }^{13}$ o lo que es lo mismo, que casi un $40 \%$ de las cargas de la administración militar cartagenera recaía teóricamente sobre canales distintos al situado, y eso sin tener en cuenta que, como veremos, en muchas ocasiones gran cantidad de impuestos locales se desviaron para los sueldos de la guarnición, debido a la insuficiencia y crónico retraso de los situados provenientes de Quito y Santa Fe. Por ello resulta a todas luces difícil sostener que el situado fuese precisamente la base de la economía de la ciudad ya que, como analizaremos seguidamente, no sólo era muy irregular, sino que no es posible apreciar una verdadera relación entre el crecimiento económico de la ciudad y los situados.

\section{Crecimiento económico local, gasto militar y situados}

Las rentas reales de Cartagena de Indias, como las de cualquier otra ciudad indiana, debían estar en relación directa con su población, y posibilidades de sostenimiento de determinados aparatos estatales, fundamentalmente una más o menos amplia administración local y una guarnición militar acorde con su importancia geoestratégica. En este sentido, Cartagena tenía amplias responsabilidades, porque de ella dependía la defensa del arco defensivo de Tierra Firme que se extendía desde Río Hacha hasta Portobelo, al tiempo que debía servir de escudo para evitar cualquier penetración en el interior del Nuevo Reino. Por definición, y teniendo en cuenta lo que hemos mencionado acerca de las rentas que reflejan verdaderamente la riqueza de una ciudad y son espejo de su potencia económica, un enclave de la importancia de Cartagena debía no sólo ser defendido por su situación, sino también por su riqueza. A lo largo del siglo XVIII la monarquía española fue rediseñando poco a poco su organigrama geoestratégico

13 Serrano: Fortificaciones y tropas..., pág. 308. 
en América, atendiendo a razones de utilidad y viabilidad. En este sentido, adquirieron conciencia de la imposibilidad de defenderlo todo, de manera que la política defensiva giró en torno a la idea de resguardar sólo los enclaves útiles y rentables económica y militarmente. Por eso, guarniciones como Portobelo o Río Hacha fueron languideciendo lentamente a lo largo del siglo: no valía la pena derrochar recursos en lugares de escasa rentabilidad y Portobelo, por ejemplo, dejó de serlo después de la desaparición de su feria comercial en 1739.

En este punto surgen los primeros interrogantes. ¿Decidió la corona defender Cartagena porque era potencialmente rica debido a sus rutas comerciales con el interior y el exterior del Nuevo Reino o sólo lo hacía por su situación geográfica? Portobelo gozaba de una excelente posición geográfica, pero la imposibilidad de generar rentas suficientes para atender una parte significativa de las defensas hizo que se mantuviera a expensas de Panamá, especialmente en el último tercio del siglo XVIII. Además, su situación estaba muy expuesta a los ataques exteriores, como lo demostró Morgan en 1670 y 1671 y posteriormente Vernon en 1739, lo que hacía que difícilmente su economía pudiera resistir semejantes envites, y, por consiguiente, se vio forzada a depender de las remisiones o subsidios exteriores. ${ }^{14}$ Cartagena estaba muy bien situada en la red de comunicaciones indianas. Basta con una lectura atenta de las descripciones hechas por algunos de los virreyes del Nuevo Reino en sus relaciones de mando para percatarse de las enormes posibilidades del territorio de Cartagena de Indias y de su entorno. ${ }^{15}$ Ahora bien, cuando se estableció su sistema defensivo de una manera permanente, algo que podemos considerar que ocurrió a finales del siglo XVII, se tuvieron en cuenta todos los factores que son necesarios para sostener con ciertas garantías una ciudad de semejante calibre, es decir, población, comunicaciones con los núcleos centrales del territorio circundante, rentas, relaciones comerciales externas e internas y posibilidades militares.

Según el censo de 1778-1780 la población de Cartagena de Indias ascendía a 13.690 personas $^{16}$ cifra que a fines de siglo subía hasta los

14 Castillero Calvo, Alfredo: Economía terciaria y sociedad : Panamá siglos XVI y XVII, Panamá, [s.n.], 1980.

15 Véase a este respecto, Colmenares, Germán (compilador): Relaciones e informes de los gobernadores de la Nueva Granada, Biblioteca Popular, Bogotá, 1989, 3 tomos.

16 Citado en McFarlane, Anthony: Colombia antes de la Independencia, El Ancora Editores, Bogotá, 1997, pág. 521. 
25.000 individuos aproximadamente. Por las mismas fechas el situado teórico de la ciudad ascendía a 30.375 pesos pagaderos por Quito y 37.236 pesos provenientes de Santa Fe. ${ }^{17}$ Cuando estos situados fueron fijados, mediante real cédula de 31 de diciembre de 1672, su guarnición fija contaba con 520 hombres, cuyo costo total ascendía a 97.136 pesos. ${ }^{18}$ Es decir, la diferencia entre lo que situaban las cajas matrices en Cartagena (67.611 pesos) y el costo total de la guarnición (97.136 pesos), y por tanto de su componente humano, debía ser sufragado por la hacienda local. Es decir, 29.525 pesos debían ser suministrados anualmente por la caja de Cartagena sólo para las pagas de su guarnición, lo que representaba casi un tercio del total de los costos de la misma, puesto que en ningún momento se hace indicación alguna del resto de gastos militares: suministros, alquileres, fortificaciones, armadas, etc. $\mathrm{O}$ lo que es lo mismo, ya en fecha tan temprana como 1672, las autoridades virreinales fijaron de antemano en casi un $30 \%$ las posibilidades de la caja de Cartagena con el objeto de poder sostener con sus propios recursos una parte al menos de sus tropas y esos recursos eran las rentas.¿Tenía sentido obligar a Cartagena a pagar el 30\% de las tropas más el resto de los gastos militares si no había recursos suficientes para ello? ¿Era lógico establecer sobre la rentas de una localidad y su provincia una carga tan pesada si no existía una hacienda saneada, aunque deficitaria en relación con los gastos de defensa?

Obviamente, resulta difícil creer que las autoridades coloniales no tuvieran en cuenta todos los factores posibles a la hora de establecer obligaciones de pago para cada una de las partes, factores que más que presumiblemente tenían que ver con la economía de un enclave tan significativo como Cartagena de Indias. De hecho, ninguna de las relaciones de mando del siglo XVIII ni ningún otro documento de los consultados, provenientes de personas públicas o privadas, menciona nada acerca de que el situado fuera el componente vital o la base económica de Cartagena, cosa que sin duda habría ocurrido, si las posibilidades de la economía local no hubieran sido suficientes para sostener parte de la maquinaria de la costosa administración militar. Es más, la tendencia a que fueran las rentas de Cartagena las que se hicieran cargo de parte de los pagos a la tropa fue in crescendo. En efecto, por cédulas de 10 de febrero de 1682 y 10 de julio de 1717 se

17 AGI, Panamá 169, informe de 7 de abril de 1701, y Santa Fe 940, informe de 11 de mayo de 1746.

18 AGI, Santa Fe 457. 
introdujo una importante novedad, ya que se estipuló que Santa Fe sólo tendría que pagar la diferencia entre la cuantía teórica del situado que debía enviar a Cartagena (37.236 pesos) y lo que fueran capaces de producir las rentas de la ciudad..$^{19}$ Esto suponía que las autoridades virreinales consideraban que la capacidad económica de Cartagena era lo suficientemente importante como para que se hicieran cargo de algo más del tercio que ya tenían obligación de aportar para el pago de sus tropas.

Lógicamente esto originó un amplio abanico de reproches mutuos entre los gobernadores de Cartagena y los virreyes, polémica que no se resolvió hasta que en 1729 se ratificó un nuevo reglamento que, aprobado el 6 de diciembre de aquel año y mandado aplicar por real orden de 22 de enero de 1730, establecía un nuevo reparto de las rentas cartageneras. En este caso, se estipuló que todos los derechos que produjesen las cajas de la ciudad se dividiesen en tres partes: una para la Real Hacienda, y, por lo tanto, para sufragar sus propios gastos ordinarios; otra para invertirlas en la construcción y arreglo de fortificaciones, y la última parte dedicada al sustento de la infantería. ${ }^{20}$ Los situados que deberían enviar Santa Fe y Quito se mantenían en las mismas cantidades que en 1672, cuando fueron creados a raíz de los ataques de Morgan a Panamá y Portobelo de dos años antes. Esta nueva disposición es sumamente interesante, ya que no sólo mantenía la misma cuantía de los situados, y, por tanto, la misma relación rentas-situados de Cartagena, sino que en realidad aumentaba las obligaciones de la hacienda cartagenera para con la administración militar. Además, fijaba de una manera nítida y clara el origen de la financiación de las fortificaciones: las rentas y derechos generados por la hacienda local. ¿Era posible considerar, por tanto, la base de la economía cartagenera un situado que jurídica y reglamentariamente estaba destinado a pagar sólo algo más del 50\% de la guarnición y que, además, no tenía relación alguna con el resto de los gastos militares? Obviamente los datos indican lo contrario. Es más, en 1736 se introdujo una nueva reordenación que dejó fijada permanentemente y hasta finales de siglo la relación jurídica entre los situados y las rentas de Cartagena.

El reglamento de este año creaba oficialmente el Batallón Fijo de Cartagena estableciendo su costo anual en 130.484 pesos, al tiempo que mantenía los situados de Santa Fe y Quito en la misma cantidad que cuan-

19 AGI, Santa Fe, 936, informe de 28 de marzo 1732.

20 Serrano: Fortificaciones y tropas..., pág. 102. 
do se instituyeron, allá por 1672. Es decir, que 64 años después los situados no se habían variado un ápice, pese a que la guarnición había ido modificando paulatinamente tanto su estructura como su número. Para compensar este evidente desfase que cargaba sobre las arcas cartageneras cada vez mayores responsabilidades de pago, se ordenaba que Santa Fe enviara anualmente el situado íntegro, sin ningún tipo de descuento sobre su cuota asignada, mientras que un artículo del nuevo reglamento establecía la posibilidad de que el gobernador pudiera utilizar para el pago de las tropas todos y cada uno de los recursos disponibles en ese momento en las arcas de la real hacienda. ${ }^{21}$ Esto suponía para la hacienda local el tener que hacerse cargo del 50\% de los sueldos de la tropa, además de gran parte de los restantes gastos militares de la plaza. Algo más tarde hubo dos nuevas modificaciones reglamentarias hasta finales de siglo. ${ }^{22}$ La de 1773 hacía que la responsabilidad de pago sobre el costo de la guarnición para la hacienda local se incrementase hasta el 70\%, mientras que los situados de Santa Fe y Quito sólo estaban obligados jurídicamente a soportar el 30\% del Fijo de Cartagena. La nueva modificación de 1784 rebajaba la responsabilidad de la hacienda hasta los niveles de 1736.

En vista de la evolución observada en el costo de la guarnición y su relación con las rentas de la ciudad, resulta evidente la imposibilidad de sostener que el situado de Cartagena no sólo servía para las pagas de su guarnición, sino que además sufragaba gran parte del resto de sus gastos militares. ¿Acaso podemos considerar como base de la economía de una ciudad una transferencia teórica de capital de 67.611 pesos para una población de 13.690 personas en 1778 sin incluir la guarnición? Recordemos que en esta fecha la hacienda cartagenera era responsable del $70 \%$ de los pagos del Regimiento Fijo, y ello sin contar con los gastos en fortificaciones, suministros, armadas y demás. Es cierto que el situado real llegado a Cartagena siempre era mayor que el teórico, pero los números deben ser tratados en su correcta coyuntura. Quito envió con meridiana puntualidad el situado teórico que se le había asignado, mientras que Santa Fe suministró desde 1760 siempre una cantidad mucho mayor que la que debía enviar

21 Serrano: Fortificaciones y tropas..., págs. 103 y 291. Expedientes del Reglamento en AGI, Santa Fe 938.

22 En 1773 se creó el Regimiento Fijo de Cartagena, cuyo costo total ascendía a 220.000 pesos, mientras que en 1784 se reestructuró el Regimiento, perdiendo uno de sus dos batallones y fijando su nuevo costo total en 136.446 pesos. Serrano: Fortificaciones y tropas..., pág. 292, y expedientes del AGI Santa Fe 945 y 949. 
según todos los reglamentos y órdenes vigentes en cada etapa. ¿Por qué? Santa Fe, como capital del virreinato, no podía sustraerse a las siempre acuciantes necesidades militares de Cartagena. Como puerta y antemural del virreinato, Cartagena tenía obligaciones impuestas que excedían con creces sus posibilidades, especialmente desde 1761, año en que la monarquía española vivió una situación de permanente estado de guerra, declarada o no, con Inglaterra. Por definición, los gastos militares en épocas de guerra o de tensión prebélica, como era el caso, no se podían calcular de antemano. Siempre eran necesarias nuevas y mejores fortificaciones, arreglos de navíos de guerra, compras de ingentes cantidades de pertrechos y vituallas, y por supuesto, refuerzos humanos en abundancia. Éste fue el caso de Cartagena. Veamos los datos:

Gasto militar de Cartagena de Indias, 1761-1788 ${ }^{23}$

\begin{tabular}{lccccr} 
& Gasto militar total & Fijo & Peninsulares & Milicias & Total sueldos \\
\hline $1761-65$ & 1.867 .782 & 591.502 & 223.677 & & 854.405 \\
$1766-70$ & 1.744 .294 & 583.221 & & & 731.968 \\
$1771-75$ & 2.084 .822 & 604.251 & 222.124 & 42.403 & \\
$1776-80$ & 2.663 .783 & 857.902 & & 468.623 & 1.586 .767 \\
$1781-85$ & 3.984 .374 & 822.775 & 419.168 & 508.062 & 2.039 .871 \\
$1786-88$ & 4.419 .009 & 336.970 & 528.652 & 140.496 & 1.317 .744
\end{tabular}

Situados de Cartagena, 1761-1800

\begin{tabular}{lrrr} 
& Situados $^{24}$ & & Situados \\
\hline $1761-1765$ & 1.061 .096 & $1781-1785$ & 1.984 .353 \\
$1766-1770$ & 715.730 & $1786-1790$ & 1.625 .554 \\
$1771-1775$ & 952.544 & $1791-1795$ & 1.532 .823 \\
$1776-1780$ & 1.772 .747 & $1796-1800$ & 1.125 .053
\end{tabular}

23 Todas las cantidades en este y demás cuadros están expresados en pesos de a ocho.

24 Las fuentes son las mismas que la de la cita anterior más AGI, Santa Fe 1097, 1098, 1099, $1100,1101,1102,1103,1104$ y 1105. 
Desgraciadamente no disponemos de los datos del gasto militar para el período comprendido entre 1788 y $1800^{25}$, aunque su falta no debilitaba un ápice las siguientes conclusiones, habida cuenta que la evolución del gasto militar cartagenero de 1788 a 1800 básicamente fue la misma que en los años finales de la década de 1780 .

Las coyunturas bélicas incidieron decisivamente en el progreso del gasto militar y en los situados pertenecientes a las cajas de Santa Fe y Quito. España estuvo en guerra declarada en el período comprendido entre 1761 y 1800 en cuatro ocasiones (1762-1763, 1779-1783, 1793-1795 y 17961802), lo que afectó directamente a la situación militar de Cartagena de Indias, amén de las distintas expediciones militares que, partiendo de esta guarnición y con sus propias fuerzas y recursos, llevó a cabo entre 1784 y $1788 .{ }^{26}$ Como estas situaciones no podían ser previstas de antemano y el clima bélico era permanente durante los últimos cuarenta años del siglo XVIII, los recursos de Cartagena se vieron sobrepasados y Santa Fe se vio "obligada" a sufragar la diferencia. Las milicias, por ejemplo, que fueron creadas con pie fijo en $1773,{ }^{27}$ siguiendo el ejemplo de Cuba, ${ }^{28}$ recibían paga sólo cuando se las ponía en activo, cosa que ocurrió con carácter permanente desde 1775. Por su parte, las tropas peninsulares arribaban a Cartagena para apoyar a la guarnición fija cada vez que la situación internacional se tornaba difícil, manteniéndose en la ciudad incluso varios años tras el fin de las hostilidades. ${ }^{29}$ Obviamente, estas unidades requerían un enorme esfuerzo financiero al que Cartagena no podía hacer frente solo con sus recursos. De ahí que Santa Fe enviara cuantiosas sumas para equilibrar sus exhaustas arcas. Una atenta observación de las cifras arriba expuestas muestra una evidente relación entre el aumento de los situados y el incremento de los costos de la tropa de Cartagena, aumento que coincide claramente con las etapas de crisis bélicas y la activación tanto de las milicias como de tropas de refuerzo venidas de la península. Por tanto, la vinculación entre situados y tropas (factor humano) se nos muestra en toda su dimensión, algo que, por otra

25 Esperamos en un próximo estudio poder ampliar nuestro trabajo con los datos completos de gasto militar de Cartagena de Indias para el mencionado período.

26 Expediciones al Darién, a las costas de Río Hacha y Santa Marta contra los indios locales.

27 Serrano: Fortificaciones y tropas..., pág. 310 y siguientes.

28 Véase a este respecto el excelente trabajo de Kuethe, Allan J: Reforma militar y sociedad en la Nueva Granada 1773-1808, Banco de la República, Santa Fe de Bogotá, 1993.

29 Entre 1761 y 1788 actuaron en Cartagena las siguientes unidades peninsulares: $2 .^{\circ}$ Batallón de Cantabria (1761-1763), 2..$^{\circ}$ Batallón de Navarra (1762-1763), 1. ${ }^{\circ}$ Batallón de Saboya (1771-1773), Regimiento de la Corona (1782-1785) y Regimiento de la Princesa (1786-1788). AGI, Santa Fe 1098, 1099, 1100, 1101, 1102 у 1103. 
parte, ya habíamos visto a través de las disposiciones oficiales. El resto de los cuantiosos gastos militares cartageneros salieron obviamente de las rentas locales y de los préstamos que intermitentemente hacían la población local y la clase comercial. En efecto, disponemos incluso de las palabras del propio Virrey Manuel Guirior sobre el uso de las rentas de Cartagena. En su instrucción de 1776 indicaba que la caja de Cartagena debía ser especialmente vigilada y cuidada de cualquier tipo de fraude $u$ omisión porque de ella se hacía "satisfacción de la tropa y obras de fortificación de aquella plaza, llave y antemural del Reino", ${ }^{30}$ añadiendo más adelante sobre las necesidades de fortificaciones de Cartagena que "de las rentas reales de la ciudad y provincia se reserven a este interesante objeto y al prest de la tropa". ${ }^{31}$

Es obvio que tanta cantidad de dinero en metálico debía discurrir y circular de una manera u otra por la ciudad y su entorno. No cabe duda de que parte del sector servicios de la ciudad se vería afectado por tal cascada de pesos, pero se nos antoja imposible que un sector tan reducido cuantitativamente como el de los artesanos, por ejemplo, pudiera generar suficiente base económica como para sostener a toda la población. La incidencia sobre las rentas locales vía impuestos lógicamente debía sentirse, pero es más que cuestionable que fuera precisamente una transferencia de capitales, por lo demás muy irregular, la que pudiera dar vida a Cartagena, sobre todo si tenemos en cuenta que el situado ha quedado claramente demostrado que servía para la paga de las tropas, y que su cuantía era excesivamente dependiente de factores externos, como eran la guerra y las expediciones militares internas.

En las tres últimas décadas del siglo, Cartagena vivió una de sus mejores etapas en lo que respecta a su economía y finanzas. Hasta la década de 1770 el comercio cartagenero se había visto muy castigado por el rígido control monopolístico impuesto desde Madrid y por la dura competencia del siempre pujante contrabando. Sin embargo, tras la Guerra de los Siete Años el gobierno de Carlos III, en gran medida alarmado por los informes provenientes del Nuevo Reino acerca de la pobreza y la falta de recursos en que se encontraba, optó por una amplia y completa modernización del comercio y las finanzas coloniales. ${ }^{32}$ La libertad de comercio empezó a tomar fuerza en la cabeza de algunos virreyes como forma de combatir el tráfico ilícito, agilizar las transacciones comerciales y aumentar las rentas mediante las aduanas e impuestos sobre la entrada y salida de productos. La

30 Colmenares: Relaciones e informes..., pág. 333.

31 Ibídem, pág. 335.

32 McFarlane: Colombia..., pág. 188. 
introducción del Reglamento de Libre Comercio en 1778 fue de hecho el triunfo de aquellos que veían en la libertad para comerciar con el extranjero una forma de aumentar el poder del Estado en América y una beneficiosa posibilidad de mejorar los réditos de las arcas neogranadinas. Con las lógicas irregularidades y fluctuaciones provocadas por la guerra a finales de la década de 1780, se podía decir que el comercio de Cartagena había conseguido despegar finalmente y ayudar en gran medida a la financiación de la maquinaria militar cartagenera. De hecho, el establecimiento de su aduana en 1780 tuvo esencialmente este fin, y la mayor parte de sus productos fueron canalizados hacia la administración militar: resultaba obvio que los situados sólo constituían una parte de los recursos que financiaban el ejército en Cartagena de Indias.

Más adelante se expondrán una serie de tablas que reflejan la evolución de las diferentes rentas de Cartagena entre 1761 y 1800.

\section{Ingresos por rentas, 1761-1800 ${ }^{33}$}

Las rentas e ingresos provenientes de la actividad comercial, como eran las del almojarifazgo, aduanas, comisos y avería muestran una extraordinaria actividad justo después de la liberalización del comercio y, muy especialmente, en las dos últimas décadas del siglo, cuando los beneficios de las exportaciones e importaciones del puerto de Cartagena se hicieron muy evidentes. Existe constancia de que los réditos de la aduana fueron esencialmente destinados al ámbito militar. Las grandes cantidades que emanan de estos impuestos son fiel reflejo de la mejoría de la actividad económica y hacendística en la Cartagena de finales del XVIII, y explican en gran medida los también grandes gastos militares que pudo afrontar la guarnición cartagenera en esta última etapa. El efecto sobre los comerciantes también fue inmediato, porque con mayores beneficios y mejor rentabilidad pudieron aportar dinero a la hacienda de Cartagena para sus empresas militares.

En esta coyuntura, el situado se mostró como un elemento cuya dinámica apenas tenía relación directa con la propia evolución de las rentas, más allá del lógico impacto por cuanto, como es natural, sabemos que forzosamente una parte de este capital debió tener cierto reflejo en la actividad económica local, y por tanto, en las rentas que de ella dimanaban.

33 AGI, Santa Fe 1097, 1098, 1099, 1100, 1101, 1102, 1103, 1104, 1105, 1106, 1107, 1108, $1109,1110,1111,1112,1113,1114$ y 1115. 
ECONOMÍA, RENTAS Y SITUADOS EN CARTAGENA DE INDIAS, 1761-1800

Alcabala Almojarifazgo Real Aduana Aguardiente Tabaco

\begin{tabular}{rrrrrr}
\hline $1761-1765$ & 27.533 & 5.480 & & 116.543 & 30.657 \\
$1766-1770$ & 82.412 & 440 & & 268.503 & 196.933 \\
$1771-1775$ & 98.460 & 1.521 & & 281.902 & 210.793 \\
$1776-1780$ & 117.863 & 2.089 & & 355.091 & 340.349 \\
$1781-1785$ & 141.442 & 645.694 & 645.075 & 401.975 & 316.211 \\
$1786-1790$ & 293.848 & 662.217 & 1.394 .160 & 876.831 & 651.652 \\
$1791-1795$ & 120.082 & 278.026 & 697.566 & 584.667 & 465.862 \\
$1796-1800$ & 129.154 & 230.554 & 376.413 & 302.958 & 572.256
\end{tabular}

\begin{tabular}{lcrrrr} 
& Sisa & Comisos & Avería & Otros & Total \\
\hline $1761-1765$ & 40.871 & 36.217 & 144.746 & 160.776 & 562.823 \\
$1766-1770$ & 35.094 & 12.118 & 122.066 & 159.719 & 877.285 \\
$1771-1775$ & 34.639 & 10.158 & 128.481 & 168.106 & 934.060 \\
$1776-1780$ & 41.935 & 6.674 & 89.206 & 231.060 & 1.184 .267 \\
$1781-1785$ & 44.218 & 10.271 & 70.964 & 199.685 & 2.475 .535 \\
$1786-1790$ & 45.644 & 13.381 & 153.744 & 188.439 & 4.279 .916 \\
$1791-1795$ & 66.927 & 164.565 & 111.972 & 615.154 & 3.104 .821 \\
$1796-1800$ & 41.638 & 64.721 & 42.447 & 436.031 & 2.196 .172
\end{tabular}

RELACIÓN ALCABALA-SITUADOS 1761-1800

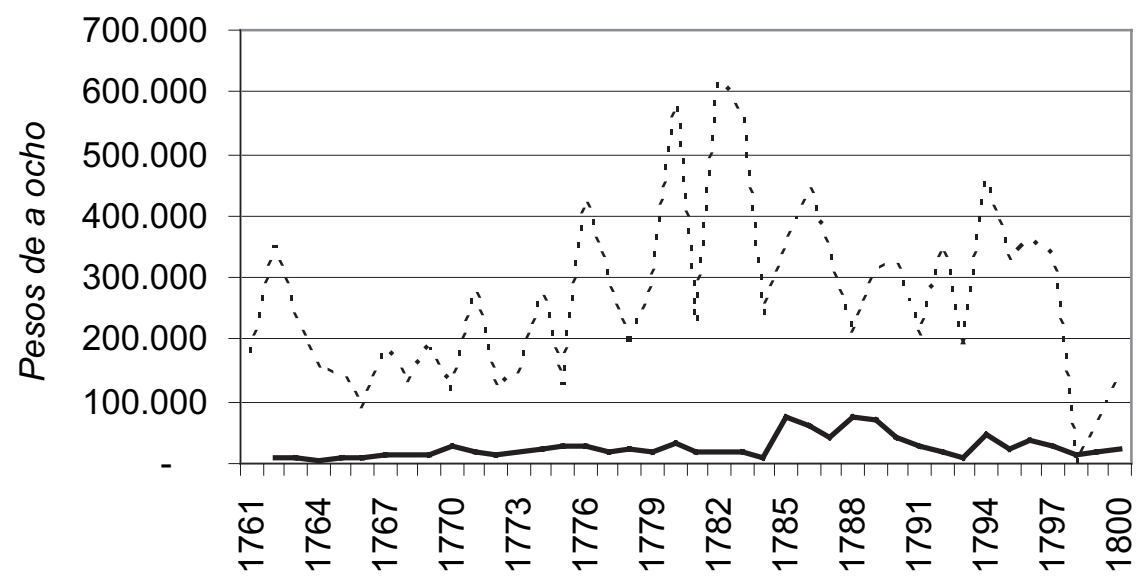

- ALCABALA -.... SITUADOS 
La gráfica anterior muestra la exacta relación entre un ingreso que era reflejo directo de los intercambios a nivel local, como fue la alcabala, y los situados. Si el situado hubiera sido parte significativa de las rentas generales de la ciudad, la alcabala indicaría esa relación de una manera directa, mostrando valores muy semejantes a los del situado. La idea de que el dinero proveniente del exterior era el motor de la economía local, pagando no sólo a las tropas sino también las fortificaciones y los gastos navales, no se sostiene a partir de los datos hasta ahora expuestos. Los ingresos por alcabala se mantuvieron muy regulares hasta la expansión de la actividad comercial a mediados de los años 1780 , cuando la tendencia fue claramente ascendente gracias, sin duda, al alto nivel de intercambios locales debido no sólo al situado, sino además de él. Las fortificaciones, pagadas como se ha visto por los impuestos locales esencialmente, fueron un aliciente para el intercambio local e interprovincial, pero, en este aspecto, el situado apenas sí incidió. Éste se mantuvo con los habituales niveles de irregularidad en una secuencia claramente dependiente de las necesidades coyunturales, algo que no hubiera sido posible si realmente el situado hubiera sido el sostén de la economía cartagenera. De hecho, la siguiente gráfica demuestra que la tendencia fue justamente la contraria:

RELACIÓN RENTAS-SITUADOS, 1761-1800

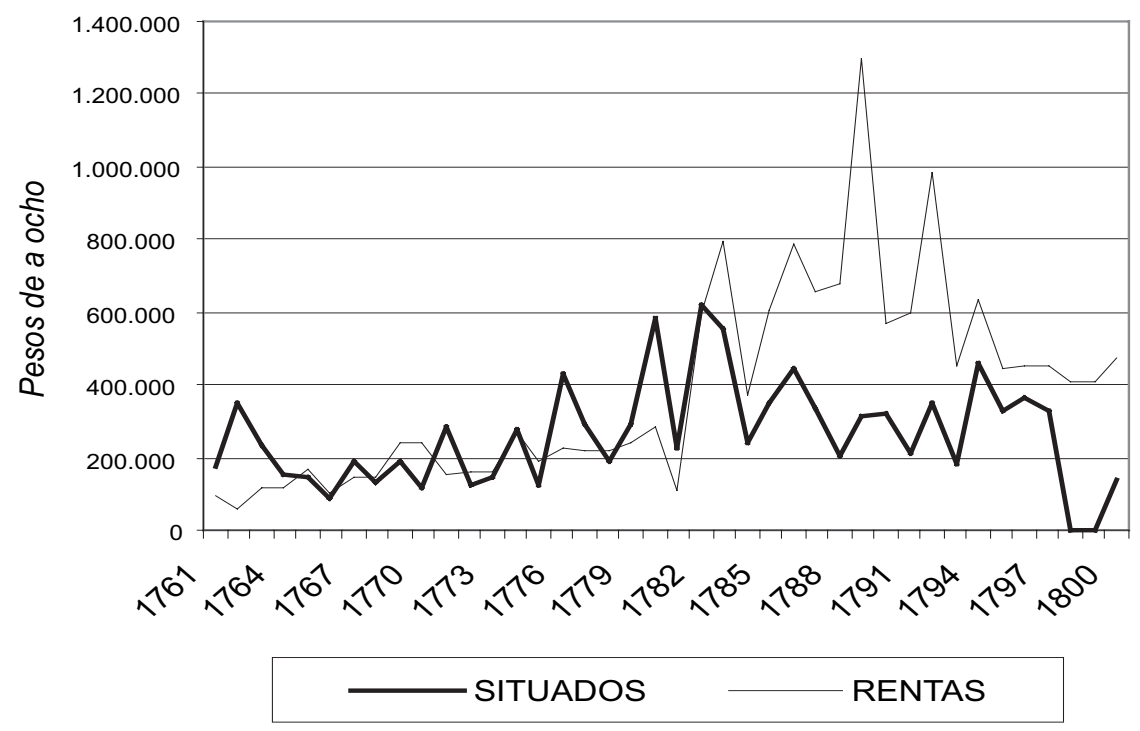


En efecto, la evolución del conjunto de las rentas de Cartagena siguió una tendencia más o menos uniforme hasta la "ruptura" de mediados de los años 1780, cuando los ingresos provenientes del comercio exterior e interior dispararon las posibilidades recaudatorias de manera evidente. Aunque se observa un descenso en los últimos años del período estudiado, la evolución general fue claramente alcista. Así se observa cierta relación entre situados y rentas en determinados años de grandes alzas fácilmente explicable por el obligado aumento de los intercambios a nivel local que, como sabemos, tienen su reflejo en determinadas rentas. Sin embargo, la evolución de las rentas es claramente independiente de la de los situados, hasta tal punto que el porcentaje de aportación del situado sobre el conjunto de los ingresos cartageneros siguió una línea nítidamente descendente como se puede comprobar en la siguiente gráfica:

PoRCENTAJE DE APORTACIÓN DEL SITUADO

AL CONJUNTO DE INGRESOS, 1761-1800

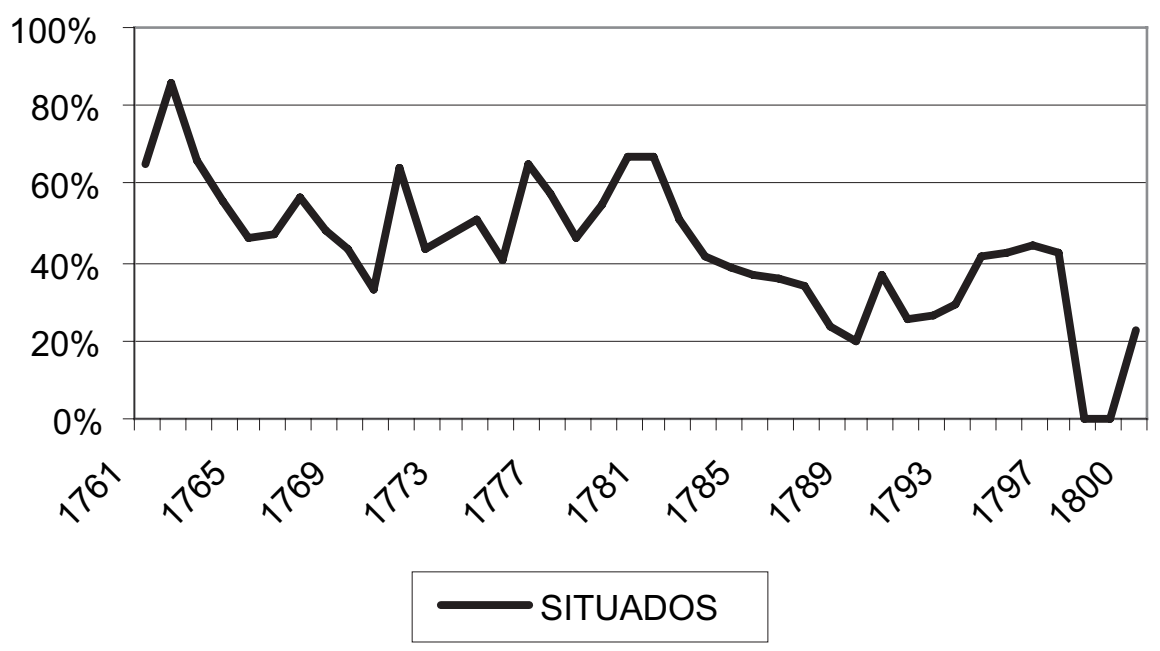

Esta es tal vez la gráfica más destacada por cuanto en ella se puede apreciar cómo fue perdiendo empuje y peso específico el situado a lo largo de los últimos cuarenta años del siglo. Efectivamente, durante los primeros años de la década de 1760 el peso del situado sobre el conjunto de los ingresos fue muy importante, hasta alcanzar en algunos momentos más del $80 \%$ 
de todos los ingresos de la hacienda local. La pobreza del comercio exterior cartagenero, incapaz de competir al mismo tiempo con los contrabandistas y contra otras regiones caribeñas mejor adaptadas al comercio internacional, y el mantenimiento del sistema monopolístico desde Madrid son las causas que explican el fuerte peso del situado sobre el conjunto de los ingresos de la ciudad. Hasta mediados de la década de 1780 este porcentaje, aunque obviamente muy irregular, se mantuvo en torno al 50\% para luego ir cayendo justo cuando sabemos que las rentas de Cartagena tuvieron un fuerte incremento gracias a la expansión del comercio favorecido, como sabemos, por las medidas aperturistas de la metrópoli. Esto nos indica no sólo que durante los últimos años del siglo XVIII el situado dejó de ser el ingreso cuantitativamente más importante, sino que además prueba la escasa relación entre éste ramo de la hacienda cartagenera y la economía local. Si los procesos de intercambios locales hubieran sido claramente dependientes del situado, los gastos militares hubieran sufrido una fuerte contracción en los últimos años del siglo. Sin embargo, sabemos que eso no sólo no ocurrió, sino que además los últimos momentos del siglo fueron especialmente expansivos en cuanto al gasto militar se refiere, y esto sólo es posible gracias a la fortaleza de las rentas locales que permitían un fuerte gasto militar sin dependencia de las transferencias exteriores. No olvidemos aquí que de las rentas locales salían la mayor parte de los gastos en fortificaciones, además de todos los suministros y una parte muy importante de los gastos navales. El situado se mantuvo alto sólo en la medida en que había muchas tropas peninsulares y milicias que mantener por el estado de guerra permanente a finales de siglo y a las costosísimas campañas militares contra los irreductibles indios del Darién y la zona de Santa Marta.

\section{Conclusiones}

Creemos que los datos expuestos constituyen la mejor conclusión de nuestro análisis. Se ha visto que el situado constituía un elemento más del entramado que financiaba la guarnición de Cartagena, pero en absoluto existen pruebas que permitan sostener que representaba la base económica o el componente esencial de los ingresos de la ciudad y su entorno. Defender esto último es negar el importante papel de la clase comerciante local, no considerar los fuertes ingresos provenientes de la actividad exportadora e importadora, y anular el papel de las rentas cartageneras como ele- 
mento equilibrador del gasto militar. Las rentas de la ciudad actuaban como factor estabilizador, porque precisamente, dependiendo de su pujanza, los gobernadores se podían ver más o menos exonerados de sus siempre importantes obligaciones militares. Con unas rentas bajas, las posibilidades de construir fortificaciones se hubieran visto frenadas, $y$, por consiguiente, los gobernadores de Cartagena hubieran podido exigir con toda razón a los virreyes santafereños aportaciones directas para sufragarlas. Sin embargo, nada de esto ocurrió. El dinero que circulaba por la ciudad sin duda fue importante y forzosamente tuvo que servir para mantener ligados al terreno a determinados artesanos sabedores de que siempre habría más o menos liquidez para sus pequeños negocios. No obstante, los datos de rentas locales indican precisamente que el impacto fue muy reducido y que el comercio fue uno de los mayores baluartes en los que se apoyó el gasto militar.

Además, existe un hecho decisivo que abona toda nuestra tesis. La falta de testimonios contemporáneos que indiquen la importancia del situado para la economía local representa un factor nada desdeñable. Si el situado hubiera sido el verdadero catalizador de la economía local, tanto virreyes como gobernadores y comerciantes nos hubieran dejado innumerables pruebas documentales. A nadie podría haber escapado un hecho de semejante importancia, especialmente porque el situado era muy irregular, lo que hubiera provocado no pocas alteraciones en los circuitos económicos locales y hubiera incitado a una amplia batería de protestas a todos los niveles. Cuando el situado es verdaderamente el elemento clave para la subsistencia de una guarnición o enclave determinados, las pruebas documentales y testimonios son, sin duda, muy abundantes.

En la última década del siglo se produjo una agria disputa entre las autoridades de Panamá y el virrey del Perú acerca de la negativa de Lima a seguir enviando los 260.000 pesos asignados como situado a Panamá. La causa de tan tajante decisión fue la remisión de un informe por un contador panameño que indicaba las posibilidades de ahorro que tenía Panamá si se efectuaban determinados ajustes en su contaduría. Hasta comprobar la viabilidad del proyecto, el virrey optó por cerrar el grifo del situado (?) algo que enfureció a los panameños sobremanera. La documentación acerca de la necesidad del situado generó abundantes documentos sobre los mismos y su relación con la economía local. En uno de ellos el administrador general de las rentas del tabaco, Felix de Soto, decía entre otras cosas “... prueba clara que convence que aquí no hay caudales particulares con que contar en ningún caso y que pobres todos y toda la provincia, negados los 
situados, no hay dinero con que prosperen los ramos de la Real Hacienda ... acabado el tal cual comercio de hoy a que da calor el situado de Lima, los vecinos todos huyendo de la pobreza y miseria a que esto quedará reducido, mudaran de domicilio y despoblado el país mas de lo que hoy está disminuirá también precisamente los presentes valores de las rentas de tabaco y aguardiente ... en consecuencia forzosa que antes de dos años en que se experimente la falta de situado, no hay ya moneda que corra" ${ }^{34}$ Ante tales alegatos, junto con muchos otros de similar naturaleza, el virrey, prudente y sabiamente, decidió seguir enviando el situado que constituía la savia de la ciudad y provincia de Panamá.

En definitiva, se puede afirmar que en Cartagena de Indias el situado fertilizaba el circuito comercial local, manteniendo viva una parte de los comercios y actividades económicas de pequeña envergadura, pero que al contrario del caso arriba señalado, aquí no constituía el elemento primordial, ni tampoco hacía de la ciudad un enclave completamente dependiente de cajas matrices externas.

Recibido el 9 de noviembre de 2005 Aceptado el 25 de mayo de 2006

34 AGI, Santa Fe 911, informe de Félix de Soto al virrey del Perú, fechado en Panamá a 27 de noviembre de 1790 . 